\title{
ANATOMIA DA MADEIRA DE ACACIA MELANOXYLON R. BR. ${ }^{1}$
}

\author{
JOSÉ NEWTON CARDOSO MARCHIORI ${ }^{2}$
}

\section{RESUMO}

São anatomicamente descritos os caracteres gerais, macroscópicos e microscópicos da madeira de Acacia melanoxylon $\mathrm{R}$. Br. A presença de raios 1 - 4-seriados e de fibras libriformes não septadas foram reconhecidas como de valor diagnóstico para o subgênero Heterophyllum Vassal, ao qual pertence a espécie em estudo.

Palavras-chave: Anatomia da madeira, Acacia melanoxylon, sub-gênero Heterophyllum Vassal.

\section{SUMMARY}

[Wood anatomy of Acacia melanoxylon R.Br.].

The general, macroscopic and microscopic wood features of Acacia melanoxylon $\mathrm{R}$. Br. are described. The presence of 1 to 4-seriate rays and of libriform non-septated fibres are presently recognized as typical to Heterophyllum Vassal, the subgenus that embraces the studied species.

Key words: Wood anatomy, Acacia melanoxylon, subgenus Heterophyllum Vassal.

\section{INTRODUÇÃO}

A literatura anatômica sobre sobre o gênero Acacia não corresponde, por escassa, à importância econômica e diversidade de espécies nativas e cultivadas no continente americano. Record \& Hess (1949), por exemplo, não fazem qualquer referência ao mesmo em seu clássico Timbers of the New World, a despeito do numeroso contingente neotropical.

Em estudo de madeiras argentinas, Cozzo (1951) não observou diferenças anatômicas importantes em 13 espécies investigadas, motivo pelo qual refere-se ao gênero com o estruturalmente homogêneo. $\mathrm{O}$ autor fornece uma diagnose anatômica para o conjunto das espécies e uma chave dicotômica para a identificação das mesmas.

Em contraste com o autor argentino, Marchiori (1980) registrou uma relativa semelhança estrutural entre Acacia tucumanensis

1 Recebido em 14-12-2008 e aceito para publicação em 23-5-2009.

2 Engenheiro Florestal, Dr., bolsista de Produtividade em Pesquisa CNPq - Brasil, Professor Titular do Departamento de Ciências Florestais, Univerwsidade Federal de Santa Maria, Santa Maria, RS, Brasil.
Gris. e Acacia bonariensis Gill. ex Hook. et Arn., pertencentes à série Vulgares Benth., e diferenças importantes entre estas e A. caven (Mol.) Mol., da série Gummiferae Benth. Para a distinção dos referidos grupos infragenéricos, o autor valeu-se da presença ou não de septos em fibras, do arranjo do parênquima axial e da morfologia dos raios.

Em estudo de 37 espécies sul-africanas, Robbertse et al. (1980) encontraram pouca variação anatômica na madeira, valendo-se da dimensão dos raios e, com menor importância, da presença de anéis de crescimento, do número de poros $/ \mathrm{mm}^{2}$ e da distribuição do parênquima axial, para a separação de subgêneros. Pelo primeiro destes caracteres, todas as 14 espécies estudadas do subgênero Aculeiferum Vassal mostraram raios estreitos (2-5-seriados), contrastando com as 23 espécies investigadas do subgênero Acacia, distintas pelos raios mais largos (4 a 14 células).

Originária do leste da Austrália, entre os paralelos de 16 e $43^{\circ} \mathrm{S}$, e em altitudes que variam do nível do mar a cerca de 1500 m (Farrel \& Ashton, 1978), Acacia melanoxylon R. Br. insere-se na série Phyllodineae e sub-série Plurinerves, de acordo com Bentham (1875, 
1876), ou no sub-gênero Heterophyllum, segundo Vassal (1972). Conhecida como blackwood, em sua pátria de origem (Ewart, 1930), como aromo ou acacia-negra, na Argentina (Burkart, 1978), e como "acácia Assis Brasil", no Rio Grande do Sul, trata-se de árvore comumente de 10 a $20 \mathrm{~m}$ de altura, mas de até $47 \mathrm{~m}$ no norte da Tasmânia, em sítios muito favoráveis (Farrel \& Ashton, 1978). Rústica e de rápido crescimento, adapta-se a qualquer tipo de solo, apresentando, todavia, o inconveniente de raízes superficiais, que dessecam muito o solo (Chanes, 1969).

A madeira, de cor marrom-escura até clara, indica-se para mobiliário (Ewart, 1930). A respeito de sua estrutura, Tuset \& Duran (1970) relacionam os seguintes caracteres gerais e anatômicos: cor castanho-escura; anéis de crescimento pouco demarcados; textura fina; porosidade difusa; poros escassos, apenas visíveis a olho nu, de diâmetro médio, e solitários ou em múltiplos de 2 ou 3; parênquima axial vasicêntrico-escasso, não visível a olho nu; e raios finos, numerosos, em distribuição irregular.

\section{MATERIAL E MÉTODOS}

O material estudado consiste de quatro amostras de madeira, conservadas nas xilotecas da Universidade Federal do Paraná (UFPR), do Instituto de Pesquisas Tecnológicas de São Paulo (IPT) e do Herbário de Ciências Florestais da Universidade Federal de Santa Maria (HDCF), com os seguintes registros:

- UFPR 1321. Procedência: Austrália. U.S. National Museum W-2.162; Xiloteca do Jardim Botânico do Rio de Janeiro, n. 3937.

- UFPR 1307. Procedência: Laboratório Xilotomia, Division Forestal, Toledo - Uruguay. IPT n. 9402.

- IPT 12.298. Rementente: Sr. Albino Carvalho, Portugal.

-HDCF 3308. Marchiori, J.N.C., n. 908. (1510-1988); Pedras Altas, Pinheiro Machado, RS.

De cada amostra foram preparados três corpos-de-prova, orientados para a obtenção de cortes anatômicos nos planos transversal, longitudinal radial e longitudinal tangencial, respectivamente. A microtomia seguiu a técnica padrão no Laboratório de Anatomia da Madeira da Universidade Federal do Paraná: os corpos-de-prova foram amolecidos por fervura em água e seccionados em micrótomo de deslizamento, regulado para a obtenção de cortes anatômicos com espessura nominal de $18 \mu \mathrm{m}$. Os cortes obtidos sofreram coloração com acridina-vermelha, crisoidina e azul-de-astra (Dujardin, 1964), foram desidratados em série alcoólica $(25 \%, 50 \%, 75 \%, 90 \%, 95 \%$, duas vezes álcool absoluto), diafanizados em xilol e montados em lâminas permanentes com "Entellan". Na confecção de lâminas de macerado, usou-se a técnica de Jeffrey (Freund, 1970), coloração com safranina e o mesmo meio de montagem.

A terminologia, número de medições e descrição da estrutura anatômica seguiram as recomendações da Copant (1973), com as modificações introduzidas por Burger (1979). As determinações estereológicas da percentagem de vasos, parênquima axial, raios e fibras, bem como da percentagem das classes de raios quanto à largura em número de células, seguiram a metodologia recomendada por Marchiori (1980). A cor da madeira foi determinada por comparação com a "Tabela de Cores para Solos" (Munsell, 1971), sob iluminação natural. As fotomicrografias foram tomadas em aparelho Carl Zeiss.

\section{DESCRIÇÃO DA MADEIRA}

Caracteres gerais:

Madeira de cerne e alburno distintos; alburno estreito, branco-amarelado (HUE $2.5 \mathrm{Y}$ 8/2) e cerne castanho-escuro (HUE 10YR 6/4). Madeira brilhante, de grã direita, não aromática, macia ao corte transversal manual, de textura média e figura homogênea.

\section{Caracteres macroscópicos:}

Parênquima axial: visível a olho nu, em pla- 
no transversal; escasso, em disposição paratraqueal vasicêntrica e simulando faixas marginais.

Raios: invisíveis a olho nu em plano transversal, finos, pouco freqüentes. Em plano longitudinal tangencial, visíveis com dificuldade sob lente, baixos, não estratificados. Espelhado dos raios, pouco contrastado.

Poros: visíveis a olho nu, pequenos a médios, pouco numerosos e em distribuição difusa, uniforme. Poros solitários e em múltiplos de 2 a 4, agrupados radialmente e em cachos. Conteúdo vermelho-escuro, presente em alguns vasos do cerne.

Camadas de crescimento: distintas, individualizadas por parênquima marginal.

Outros caracteres: canais secretores axiais, máculas medulares, líber incluso, estratificação e canais secretores horizontais, ausentes.

Caracteres microscópicos:

Vasos: pouco numerosos $\left(1-5-11 / \mathrm{mm}^{2}\right.$; $\mathrm{s}=2,06$ ), ocupando $7,6 \%$ da seção transversal da madeira. Poros em distribuição difusa, uniforme; predominantemente solitários (Figura 1A), menos comumente em múltiplos radiais de 2 a 6, raro em cachos (Figura 1A). Poros de seção oval (Figura 1A, D), de diâmetro pequeno a médio $(77-115-170 \mu \mathrm{m} ; \mathrm{s}=22,44)$ e de paredes finas $(2-3-5 \mu \mathrm{m} ; \mathrm{s}=0,75)$. Elementos vasculares muito curtos até curtos $(200$ - 303 $440 \mu \mathrm{m} ; \mathrm{s}=46,78)$, com placas de perfuração simples, transversais a levemente oblíquas em relação ao vaso. Apêndices curtos (12 - 45 - 93 $\mu \mathrm{m} ; \mathrm{s}=21,53)$, geralmente em uma das extremidades. Espessamentos espiralados, ausentes. Pontoações intervasculares ovais, ornamentadas e de diâmetro médio $(6-7-9 \mu \mathrm{m}$; $\mathrm{s}=0,78)$, com abertura lenticular, horizontal, inclusa. Pontoações raio-vasculares arredondadas, pequenas até médias $(4-6,7-9 \mu \mathrm{m} ; \mathrm{s}=1,05)$; pontoações parênquimo-vasculares (Figura 2D), semelhantes às intervasculares $(5,5-7-9 \mu \mathrm{m}$; $\mathrm{s}=0,81)$. Conteúdo com aspecto de gomo-resina, abundante em vasos de cerne (Figura 2B). Tilos, ausentes.
Raios: numerosos até muito numerosos (5 8,5 - 15/mm; s = 1,71), ocupando $9 \%$ do volume da madeira. Tecido radial homogêneo, composto inteiramente de células horizontais (Figura 2A,B). Raios de relacionamento normal; raios agregados e fusionados, ausentes (Figura 2. C,D). Raios unisseriados, pouco frequientes (23,3\% do total), muito baixos (15 - $90-185$ $\mu \mathrm{m} ; \mathrm{s}=39,41)$, extremamente finos $(6-11-$ $16 \mu \mathrm{m} ; \mathrm{s}=2,05$ ) e com 1 a 12 células de altura (Figura 2C, D). Raios multisseriados, em sua maioria com 2 células de largura $(60,2 \%$ do total), menos comumente trisseriados $(16,3 \%$ dos raios), raro tetrasseriados $(0,2 \%)$; baixos ( $90-$ $212-468 \mu \mathrm{m} ; \mathrm{s}=77,03)$, variam de muito finos a finos $(10-20-40 \mu \mathrm{m} ; \mathrm{s}=5,19)$, com 6 14 - 30 células de altura (Figura 2C, D). Células cristalíferas, envolventes, eretas, esclerosadas, latericuliformes, oleíferas e quadradas, ausentes. Gomo-resina, abundante em células horizontais.

Parênquima axial: paratraqueal vasicêntrico (Figura 1C, D), em linhas marginais (Figura 1B) e apotraqueal difuso, representando $6,2 \%$ da seção transversal. Células fusiformes, de 175 $313-460 \mu \mathrm{m}(\mathrm{s}=63,41)$ de altura, por $11-19$ - $38 \mu \mathrm{m}(\mathrm{s}=5,39)$ de largura. Séries de parênquima com $190-320-423 \mu \mathrm{m}(\mathrm{s}=47,59)$ de altura total, por $8-22-45 \mu \mathrm{m}(\mathrm{s}=7,17)$ de largura, compostas por 2 a 4 células (Figura 2.C,D). Cristais romboédricos com cerca de 30 $\mu \mathrm{m}$, dispostos em séries de 14 a 18 câmaras, tanto na periferia do parênquima paratraqueal como dispersas no tecido fibroso.

Fibras: tecido fibroso proeminente, representando cerca de $77 \%$ da seção transversal. Fibras libriformes, não septadas (Figura 2.B, D), com pontoações simples, diminutas. Fibras cur$\operatorname{tas}(860-1105-1530 \mu \mathrm{m} ; \mathrm{s}=132,02)$, estreitas $(10-17-31 \mu \mathrm{m} ; \mathrm{s}=4,45)$ e de paredes delgadas $(1,3-2,3-3,8 \mu \mathrm{m} ; \mathrm{s}=0,59)$. Fibras gelatinosas, abundantes (Figura 1.D).

Outros caracteres: anéis de crescimento distintos, marcados por fibras radialmente estreitas no lenho tardio e por fina linha paren- 

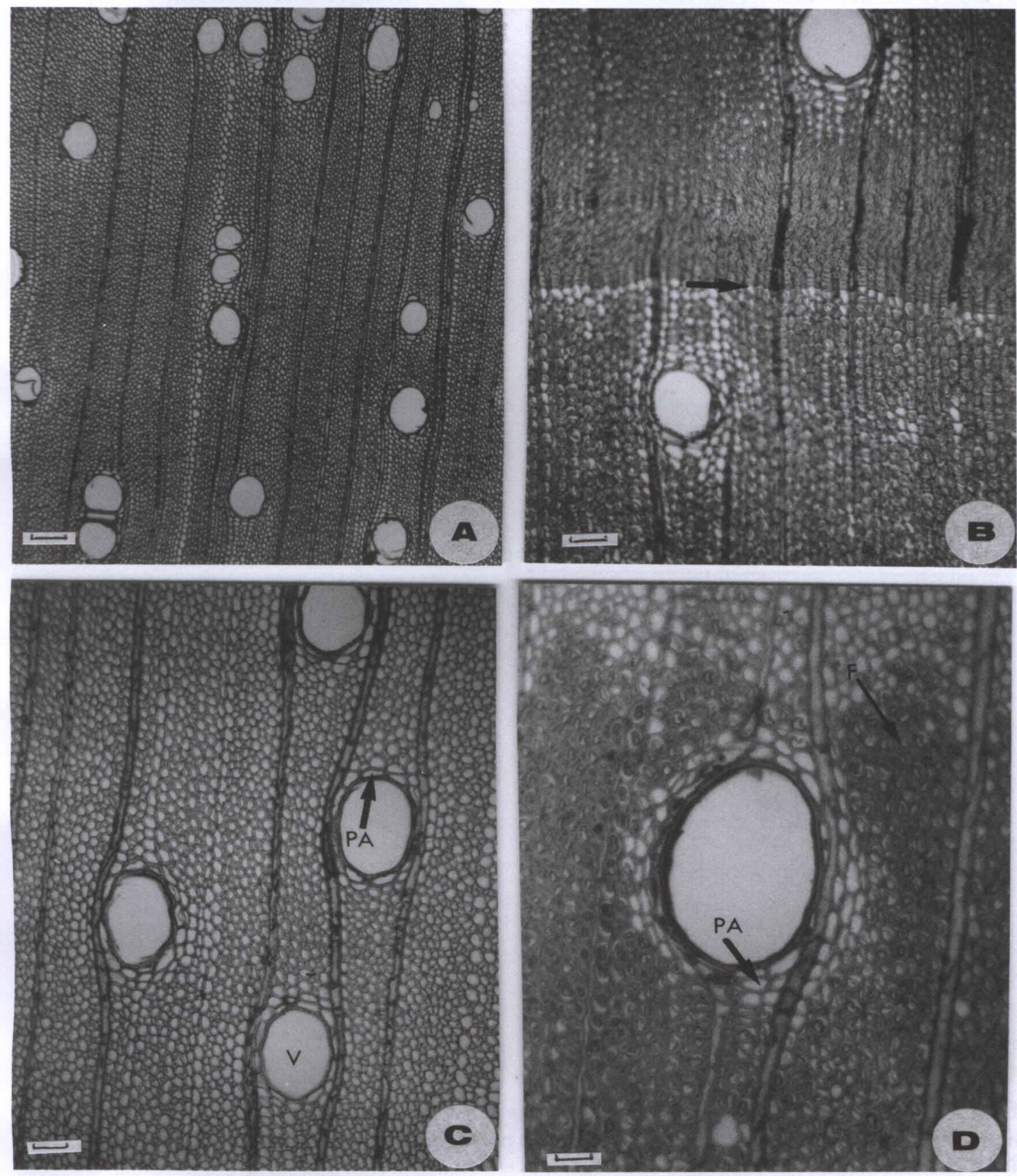

FIGURA 1 - Aspectos anatômicos da madeira de Acacia melanoxylon, em seção transversal. A - Porosidade difusa, uniforme, e vasos de seção oval, comumente solitários. B - Limite de anel de crescimento (seta), vasos ovais e parênquima paratraqueal vasicêntrico. C - Vasos ovais, solitários (V), e parênquima paratraqueal vasicêntrico (PA). D - Vaso com parênquima paratraqueal (PA), ao centro do campo, raios finos e fibras gelatinosas abundantes (F). Escala $=125 \mu \mathrm{m}(\mathrm{A}) ; 60 \mu \mathrm{m}(\mathrm{B}) ; 40 \mu \mathrm{m}(\mathrm{C}) ; 12,5 \mu \mathrm{m}(\mathrm{D})$. 

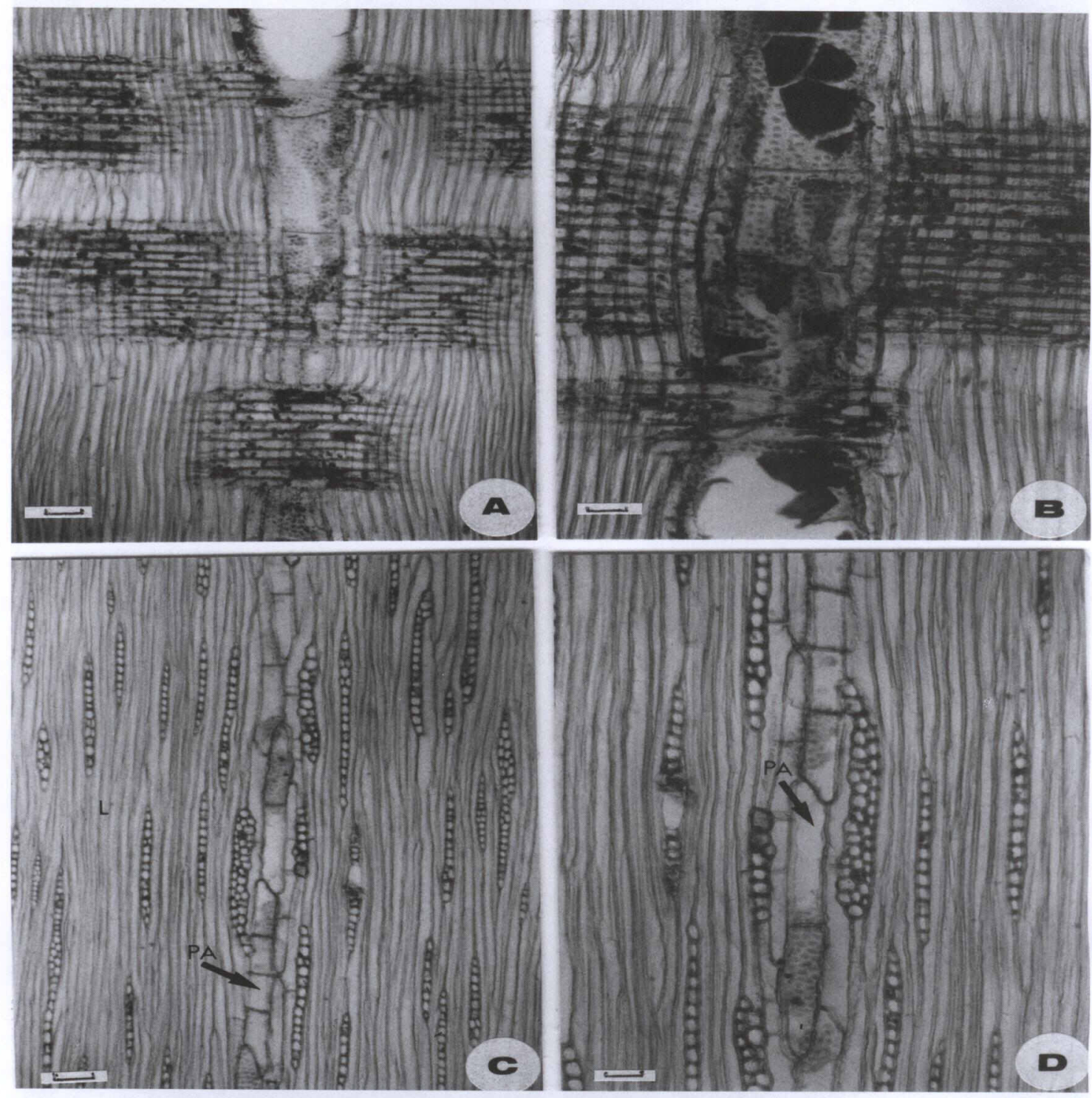

FIGURA 2 - Aspectos anatômicos da madeira de Acacia melanoxylon, em seções longitudinais. A - Raios homogêneos, de células procumbentes, com vaso e parênquima axial ao centro do campo (seção radial). B - Fibras libriformes não septadas e vaso obstruído por conteúdo com aspecto de gomo-resina, em seção radial. C - Séries de parênquima axial (PA) compostas de $2-4$ células, e raios finos, em sua maioria uni e bisseriados (seção tangencial). D - Detalhe de parênquima axial seriado, raios finos e fibras libriformes não septadas (seção tangencial). Escala $=40 \mu \mathrm{m}(\mathrm{A}, \mathrm{C}) ; 12,5 \mu \mathrm{m}(\mathrm{B}, \mathrm{D})$. 
quimática no início do anel seguinte (Figura 1.B). Canais secretores, tubos laticíferos e taniníferos, líber incluso, máculas medulares e estratificação, ausentes.

\section{ANÁLISE DA ESTRUTURA ANATÔMICA}

A estrutura anatômica da madeira de Acacia melanoxylon $\mathrm{R}$. Br. distingue-se, facilmente, de três espécies do gênero, nativas no Rio Grande do Sul: Acacia caven (Marchiori, 1980, 1992), A. bonariensis (Marchiori, 1980, 1996) e $A$. tucumanensis. (Marchiori, 1980, 1994). Destas duas últimas, integrantes da série Vulgares Benth. (ou sub-gênero Aculeiferum Vassal), o material em estudo separa-se, prontamente, por ter fibras não septadas. Comparada a Acacia caven, integrante da série Gummiferae Benth. (ou sub-gênero Acacia Vassal), Acacia melanoxylon difere, sobretudo, pelos raios finos (até 4 células de largura), bem como pelas fibras de paredes relativamente estreitas, pouco contrastadas em relação ao parênquima axial, em plano transversal.

Os caracteres anatômicos acima referidos para duas espécies nativas do sub-gênero Aculeiferum Vassal (ou série Vulgares Benth.), receberam confirmação, em estudos posteriores, com outras espécies do mesmo grupo: Acacia recurva Benth. (Marchiori, 1982), Acacia nitidifolia Speg. (Marchiori, 1991a), Acacia plumosa Lowe (Marchiori, 1991b) e Acacia velutina DC. (Marchiori, 1995). Os caracteres anteriormente referidos para Acacia caven, por sua vez, foram, igualmente, observados em Acacia ibirocayensis (Marchiori, 1983), confirmando seu valor taxonômico para a série Gummiferae Benth. (ou sub-gênero Acacia Vassal).

Pertencente à série Phyllodineae Benth. (ou sub-gênero Heterophyllum Vassal), Acacia melanoxylon, difere de todas as espécies nativas acima comentadas. A presença de fibras não septadas e com paredes relativamente finas, bem como de raios estreitos (até 4 células), foi tam- bém observada em Acacia mearnsii (Costa \& Marchiori, 1980), Acacia longifolia (Illana \& Marchiori, 1980), bem como em Acacia podalyriaefolia, A. dealbata e A. decurrens (Marchiori, 1990), todas incluídas no subgênero Heterophyllum Vassal, confirmando seu valor diagnóstico para o grupo taxonômico em questão.

\section{REFERÊNCIAS BIBLIOGRÁFICAS}

BENTHAM, G. Revision of the sub-order Mimoseae. Trans. Linn. Soc. London, n. 30, p. 335-664, 1875.

BENTHAM, G. Leguminosae. III. Mimoseae. In: MARTIUS, C.F.P. de. Flora brasiliensis. v. 15, n. 2, p. 259-527, 1876.

BURGER, L.M. Estudo anatômico do xilema secundário de sete espécies nativas do gênero Dalbergia, Leguminosae-Faboideae. Curitiba: UFPR, 1979. 184 f. Dissertação (Mestrado em Engenharia Florestal) - Universidade Federal do Paraná.

BURKART, A. Leguminosas. In: DIMITRI, M.J. Enciclopedia argentina de Agricultura y Jardineria. Buenos Aires: ACME, 1978. v. 1. p. 467-538.

CHANES, R. Deodendron - Arboles y arbustos de jardín en clima templado. Barcelona: Ed. Blume, 1969. 545 p.

COPANT. Comissão Panamericana de Normas Técnicas. Descrição macroscópica, microscópica e geral da madeira - Esquema I de recomendação. Colômbia, 1973. 19 p. (COPANT 30).

COSTA, A.F.; MARCHIORI, J.N.C. Estudo anatômico da madeira de Acacia mearnsii De Willd. In: Congresso Florestal Estadual, IV. Anais. Nova Prata, 1980. p. 237-245.

COZZO, D. Anatomia del leño secundario de las leguminosas mimosoideas y caesalpinoideas argentinas silvestres y cultivadas. Rev. Inst. Nac. Invest. Ci. Nat. Ci. Bot., v. 2, n. 2, p. 63-290, 1951.

DUJARDIN, E.P. Eine neue Holz-Zellulosenfaerbung. Mikrokosmos, n. 53, p. 94, 1964.

EWART, A.J. Flora of Victoria. Melbourne: H.J. Green, 1930. 1527 p.

FARREL, T.P.; ASHTON, D.H. Population studies on Acacia melanoxylon $\mathrm{R}$. Br. 1. Variation in seed and vegetative characteristics. Australian Journ. Bot., n. 26, p. 365-379, 1978. 
FREUND, H. Handbuch der Mikroskopie in der Technik. Frankfurt: Umsham Verlag, 1970.379p.

ILLANA, H.A.; MARCHIORI, J.N.C. Estudo anatômico do xilema secndário de Acacia longifolia (Andr.) Willd. In: Congresso Florestal Estadual, IV. Anais. Nova Prata, RS, 1980. p. 207-215.

MARCHIORI, J.N.C. Estudo anatômico do xilema secundário de algumas espécies dos gêneros Acacia e Mimosa, nativas no Estado do Rio Grande do Sul. Curitiba: UFPR, 1980. $186 \mathrm{f}$. Dissertação (Mestrado em Engenharia Florestal) - Universidade Federal do Paraná.

MARCHIORI, J.N.C. Estudo anatômico do xilema secundário e da casca de Acacia recurva Benth. (Leguminosae Mimosoideae). Ciência e Natura, Santa Maria, v. 4, p. 95-105, 1982.

MARCHIORI, J.N.C. Anatomia das madeiras do gênero Acacia, nativas e cultivadas no Estado do Rio Grande do Sul. Curitiba, UFPR, 1990. 226 f. Tese (Doutorado em Engenharia Florestal) - Universidade Federal do Paraná.

MARCHIORI, J.N.C. Anatomia da madeira de Acacia nitidifolia Speg. (Leguminosae Mimosoideae). Ciência Florestal, Santa Maria, v. 1 , n. 1, p. 46-63, 1991a.

MARCHIORI, J.N.C. Anatomia da madeira de Acacia plumosa Lowe (Leguminosae Mimosoideae). Ciência e Natura, Santa Maria, v. 13 , p. $67-77,1991$ b.

MARCHIORI, J.N.C. Anatomia da madeira e casca do espinilho, Acacia caven (Mol.) Mol. Ciência Florestal, Santa Maria, v.2, n. 1, p. 27-47, 1992.

MARCHIORI, J.N.C. Estudo anatômico do xilema secundário de Acacia ibirocayensis Marchiori (Leguminosae Mimosoideae). Ciência e Natura, Santa Maria, v. 15, p. 149-159, 1993.

MARCHIORI, J.N.C. Anatomia da madeira e casca de Acacia tucumanensis Gris. Ciência e Natura, Santa Maria, v. 16, p. 85-104, 1994.

MARCHIORI, J.N.C. Anatomia da madeira e casca de Acacia velutina DC. Ciência e Natura, Santa Maria, v. 17, p. 99-114, 1995.

MARCHIORI, J.N.C. Anatomia da madeira de Acacia bonariensis Gill. ex Hook. et Arn. Ciência Rural, Santa Maria, v. 26, n. 2, p. 209-216, 1996.

METCALFE, C.R.; CHALK, L. Anatomy of the Dicotyledons. Oxford: Clarendon Press, 1972. $1500 \mathrm{p}$.

MUNSELL COLOR DIVISION. Soil Color Charts. Baltimore, 1971. s.p.

RECORD, S.J.; HESS, R.W. Timbers of the New World. New Haven: Yale University Press, 1949. $640 \mathrm{p}$.

ROBBERTSE, P.J.; VENTER, G.; RENSBURG, H.J. van. The wood anatomy of the south african Acacias. IAWA Bulletin, v. 1, n. 3, p. 93-103, 1980.

TUSET, R.; DURAN, F. Descripcion y clave macroscopicas de maderas comerciales en Uruguay. Montevideo: Universidad de la Republica, Facultad de Agronomia, 1970, 63 p. (Bol. N. 114)

VASSAL, J. Ontogenetic and seed research applied to the morphological, taxonomical and phylogenetic study of the genus Acacia. Travaux Lab. For. Toulouse, v. 1, n. 8, p. 1-125, 1972. 